\title{
Modelling soil water dynamic in rain-fed spring maize field with plastic mulching
}

\author{
Baoqing Chen ${ }^{\mathrm{a}, \mathrm{b}, \mathrm{c}}$, Enke Liu ${ }^{\mathrm{a}, \mathrm{b}}$, Xurong Mei ${ }^{\mathrm{a}, \mathrm{b}}$, Changrong Yan ${ }^{\mathrm{a}, \mathrm{b}, *}$, Sarah Garréc \\ a Key Laboratory for Prevention and Control of Residual Pollution in Agricultural Film/Key Laboratory for Dryland Farming Agriculture, Ministry of \\ Agriculture of the People's Republic of China (MOA), Beijing, 100081, PR China \\ ${ }^{\mathrm{b}}$ Institute of Environment and Sustainable Development in Agriculture, Chinese Academy of Agriculture Sciences, Beijing, 100081, PR China \\ ${ }^{\mathrm{c}}$ Terra Research Center, Gembloux Agro-Bio Tech, University of Liège,Passage des Déportés, 2, Gembloux, Belgium
}

\section{A R T I C L E I N F O}

\section{Article history:}

Received 12 July 2017

Received in revised form 3 December 2017

Accepted 8 December 2017

\section{Keywords:}

Soil water

Hydrus 2D

Canopy redistribution

Rainfall infiltration

Spatial variation

\begin{abstract}
A B S T R A C T
Numerical solution of the Richards equation with Hydrus-2D model is a low cost and fast way to get information on spatio-temporal soil water dynamics. Previous researches with Hydrus-2D have developed two different approaches to represent the rainfall infiltration in irrigated field with plastic mulching: 'BP' - an approach comprised by bare strip boundary and plastic strip boundary without consideration of film side infiltration;'BP+'- an approach comprised by bare strip and plastic strip with integrating the process of film side infiltration by increasing the rainfall infiltration amount in bare strip. Nevertheless, the performance of these approaches has not yet been evaluated in rain-fed fields. Considering much more dominant role of rainfall infiltration in rain-fed agriculture, we tested an additional approach which comprised a bare strip, plastic strip and planting hole (BPH) to take into account the effect of the rainfall canopy redistribution and film side infiltration, and we compared its performance to the two existing approaches. Results suggested BP completely failed to reproduce the soil water content (SWC) in all soil layers of plastic strip and in the deep soil layers of bare strip. BP+ overestimated the SWC in $0-20 \mathrm{~cm}$ of the bare strip, while the performance of BPH was acceptable in different positions. After that, we compared the soil water distribution between no-mulched field (NM) and plastic mulched field (PM) with approach BPH. Our simulation showed that the highest SWC in PM occurred near the planting hole, SWC in the center zone of plastic strip was lower, while SWC in the bare strip was lowest. PM improves the soil water availability not only in the plastic strip but also in the bare strip as compared to NM.
\end{abstract}

(c) 2017 Elsevier B.V. All rights reserved.

\section{Introduction}

Rain-fed agriculture, makes up approximately $80 \%$ of global cropland and produces $60-70 \%$ of the world's food (Falkenmark and Rockström, 2004; Rost et al., 2008). It plays a dominant role in the global food supply, especially considering the increasing global water shortage (Rockström et al., 2010). In China, rainfed agriculture accounts for approximately 25 Mha of the arable land and is mainly located on the semi-arid Loess Plateau and in northeast China, where the crop yields are limited by the soil water deficit and the low soil temperatures in the spring (Deng et al., 2006;

\footnotetext{
* Corresponding author at: Key Laboratory for Prevention and Control of Residual Pollution in Agricultural Film/Key Laboratory for Dryland Farming Agriculture, Ministry of Agriculture of the People's Republic of China (MOA), Beijing, 100081, PR China.

E-mail address: yanchangrong@caas.cn (C. Yan).
}

Xiao et al., 2016). Plastic mulching has become a popular agricultural technology in those area, since it is thought to maintain soil moisture and increase the soil temperature (Tarara, 2000; Kader et al., 2017). For economic reasons, farmers usually do not cover the entire field with plastic film, but use polyethylene (PE) plastic strips which are alternated with bare strips, a technique called partial plastic mulching.

Soil water dynamics in fields with plastic mulching has received wide attention (Fisher, 1995; Wu et al., 2017; Ren et al., 2017; Dong et al., 2009; Zhao et al., 2012), since not only crop performance, but also environmental processes such as nitrate leaching and the emission of greenhouse gasses depend heavily on soil moisture dynamics (Qin et al., 2015; Filipovic et al., 2016; Liu et al., 2016). Measurement methods such as gravimetric soil water determination on soil samples and time domain reflectometry, and simulations have been used to obtain information on soil water dynamics and distribution (Wu et al., 
2017; Ren et al., 2017; Filipovic et al., 2016; Li et al., 2015; Liu et al., 2013). Compared to field measurements, modelling studies are low-cost and present a high temporal and spatial resolution.

Models that can be used to obtain soil water information mainly include WaSim-ETH, Community Land Model, SiSPATIsotope, Hydrus and crop models such as SWAP, CERES, WOFOST and Aquacrop (Vereecken et al., 2016). Hydrus is mainly used at the pedo up to field scale. Crop models are mainly applied at field scale or regional scale, while the WaSim-ETH, Community Land Model, SiSPAT-Isotope are mainly applied at catchment scale or landscape scale. In fileds with plastic mulching, the different water infiltration and evaporation characteristics of plastic strips and bare strips may lead to obvious inhomogeneous soil water distribution. However, the soil water transport modules in most crop models are one-dimensional, and they are un-able to describe the spatial variation of soil water. Soil hydraulic model such as Hydrus-2D model can solve this problem by applying different type of boundary conditions for the plastic strip and bare strip. For these reasons, the Hydrus-2D model was adopted for the current study.

Hydrus-2D has been widely used to simulate soil water dynamic in irrigated field with plastic mulching, but not yet under rain-fed conditions. Different from the irrigated field, rainfall is the only source of soil water in the rain-fed field and a good understanding of rainfall infiltration processes is decisive for a correct prediction of the spatio-temporal patterns of soil water. In case of partial plastic mulching, rainfall can infiltrate into the soil through three pathways: (i) interception by maize leaves and transfer along the stem into the planting hole (i.e. canopy redistribution). Rainfall that is not intercepted by the maize leaves will (ii) reach the ground directly and infiltrate into the bare soil, or (iii) reach the surface of the plastic film and flow towards the bare soil and infiltrate into the soil at the film side (film-side infiltration)(Chen et al., 2017). Previous studies have applied two approaches to represent the rainfall infiltration in irrigated fields with plastic mulching: (i) In arid regions (annual rainfall amount $<200 \mathrm{~mm}$ ), Han et al. (2015), Li et al. (2015) and Liu et al. (2013) simplified reality by neglecting canopy redistribution and film side infiltration. They assumed that rainfall directly reached the bare strip and infiltrated there (without canopy redistribution) and they omitted rainfall that reached the plastic strip; (ii) In the humid regions (annual rainfall amount $>800 \mathrm{~mm}$ ), Filipovic et al. (2016) and Dusek et al. (2010) also neglected canopy redistribution, but integrated the process of film side infiltration by increasing the rainfall infiltration amount in bare strip with a factor which was equal to the ratio of plastic strip width to bare strip width. However, the performance of those two methods has not been evaluated under rain-fed conditions, where the redistribution may play an even bigger role, since no additional water is added under the plastic sheets through irrigation tubes.

In this study, we developed and applied a modelling strategy taking into account of both canopy redistribution and film side infiltration in field with plastic mulching. The objectives of this study were therefore (i) to compare the performance of different simulation strategies on reproducing soil water dynamic in rain-fed field with plastic mulching; (ii) to quantify the spatial variation of the SWC in rain-fed field with plastic mulching using the optimized simulation strategy. We hypothesized that rainfall redistribution and film side infiltration play important roles in soil water dynamics, and are not negligible under rain-fed conditions. In this study, the performance of Hydrus-2D was tested with 2 years of field data from a spring maize (Zea may L.) field that located on the Loess Plateau of China. We chose to focus on maize, since it was one of the main crops in the studied region and of great importance for Chinese agriculture (38.1 million $\mathrm{hm}^{2}$ in China in 2015 (NBSC (National Bureau of Statistics of China), 2016)).

\section{Materials and methods}

\subsection{Research site}

The research site $\left(37^{\circ} 45^{\prime} \mathrm{N}, 113^{\circ} 12^{\prime} \mathrm{E}, 1202 \mathrm{~m}\right.$ altitude $)$ is located at the Shouyang County which belongs to Shanxi Province, on the eastern part of the Loess Plateau, about $500 \mathrm{~km}$ west from the China's capital Beijing. The majority of the farmland in Shouyang County produces crops, especially maize, soy bean and potato. The research area is characterized by a semiarid temperate continental monsoon climate with four distinct seasons. According to the weather record from Shouyang weather station, which is located at $15 \mathrm{~km}$ from our research site, the experimental site has a mean annual air temperature of $7.4^{\circ} \mathrm{C}$, a mean annual frost-free period of 140 days and a mean annual rainfall amount of $480 \mathrm{~mm}$ during the past 48 years (year 1967-2014). During the experimental year 2015 and 2016, the rainfall amount was $386 \mathrm{~mm}$ and $461 \mathrm{~mm}$, which was $20 \%$ and $4 \%$ lower than the historical mean, respectively.

The soil texture is sandy loam, and the soil is classified as a calcaric Cambisol according to the World Reference Base for soil resources (FAO, 2006). The upper $20 \mathrm{~cm}$ of soil has a $\mathrm{pH}$ of 7.8 , a soil organic matter content of $18.03 \mathrm{~g} \mathrm{~kg}^{-1}$, total $\mathrm{N}$ of $0.85 \mathrm{~g} \mathrm{~kg}^{-1}$. The soil profile has three horizons: $0-20 \mathrm{~cm}, 20-60 \mathrm{~cm}$ and $60-100 \mathrm{~cm}$, and their soil texture parameters are shown in Table 1. The topography of experimental field is flat, and the groundwater is at depths deeper than $150 \mathrm{~m}$ below the surface (Gong et al., 2017). For the soil hydraulic parameters, please see 2.5.2.

Spring maize (Zea mays L.) is sown every year on the research site, and typically no crop rotation is applied. Usually, maize is sown in late April or early May and harvested in early October. After harvest, there is a fallow period until sowing in the next year. The early stage of maize growing season is usually characterized by low temperature and few rainfall and accompanied by high risk of spring drought and spring chill, and high temperature and heavy rainfall mainly happen at the middle of maize growing season, while temperature and rainfall become lower at the late growing season (Gong et al., 2015). In 2015, the maize was sown in May 1 st and harvested in September 30th, and in 2016, the maize was sown in May 5th and harvested in October 1st.

\subsection{Field experiment}

Two treatments were selected in this study: a no mulch system (NM) and a partial plastic mulching system (PM). Each treatment has three replications, and each replication was carried out in a plot with a width of $6 \mathrm{~m}$ and a length of $10 \mathrm{~m}\left(60 \mathrm{~m}^{2}\right)$. As shown in Fig. 1, the PM system included a plastic strip with a width of $80 \mathrm{~cm}$ and a bare strip with a width of $40 \mathrm{~cm}$. PE film with thickness of $10 \mu \mathrm{m}$ was applied in the PM treatment. For both the PM and NM treatments, the planting spacing was $30 \mathrm{~cm}$, the row distance was $60 \mathrm{~cm}$ and the sowing density was 56,000 plants/ha. For the detailed filed management practices in NM and PM, please see Chen et al. (2017).

During the growing season, the soil water content was determined gravimetrically to a depth of $1 \mathrm{~m}$ at $0.1-\mathrm{m}$ intervals at the middle of plastic strip and at the middle of bare strip (Fig. 1). Theoretically, the higher temporal resolution the soil moisture measurement was, the more favorable for the model evaluation. However, considering the cost of gravimetric determination and the rare rainfall in semi-arid area, the soil moisture was measured every 10 days. When the weather did not allow sampling at the planned date (e.g., due to heavy rainfall), sampling was postponed for 1-2 days. As Hydrus-2D do not include the crop growth module, we used the measured leaf area index (LAI) to calculate the potential evaporation and transpiration together with the field-recorded 
Table 1

Soil physical properties at the research site.

\begin{tabular}{|c|c|c|c|c|c|}
\hline Soil layer $(\mathrm{cm})$ & Sand $^{\mathrm{a}}(\%)$ & Silt (\%) & Clay (\%) & Bulk density $^{\mathrm{b}}\left(\mathrm{g} / \mathrm{cm}^{3}\right)$ & Totalporosity $(\%)$ \\
\hline $0-20$ & 54.9 & 29.5 & 15.6 & 1.34 & 49.4 \\
\hline $20-60$ & 55.6 & 28.2 & 16.2 & 1.45 & 45.2 \\
\hline $60-100$ & 50.0 & 31.2 & 18.8 & 1.39 & 47.5 \\
\hline
\end{tabular}

a Average of three measurements. Measured by the sieving method, sand $(0.05-2 \mathrm{~mm})$, silt $(0.002-0.05 \mathrm{~mm})$, and clay ( $<0.002 \mathrm{~mm})$.

b Measured by the cutting ring method.

c Calculated as 1-BD/PD, where BD is the soil bulk density and PD is the particle density (assumed to be $2.65 \mathrm{~g} \mathrm{~cm}^{-3}$ ).
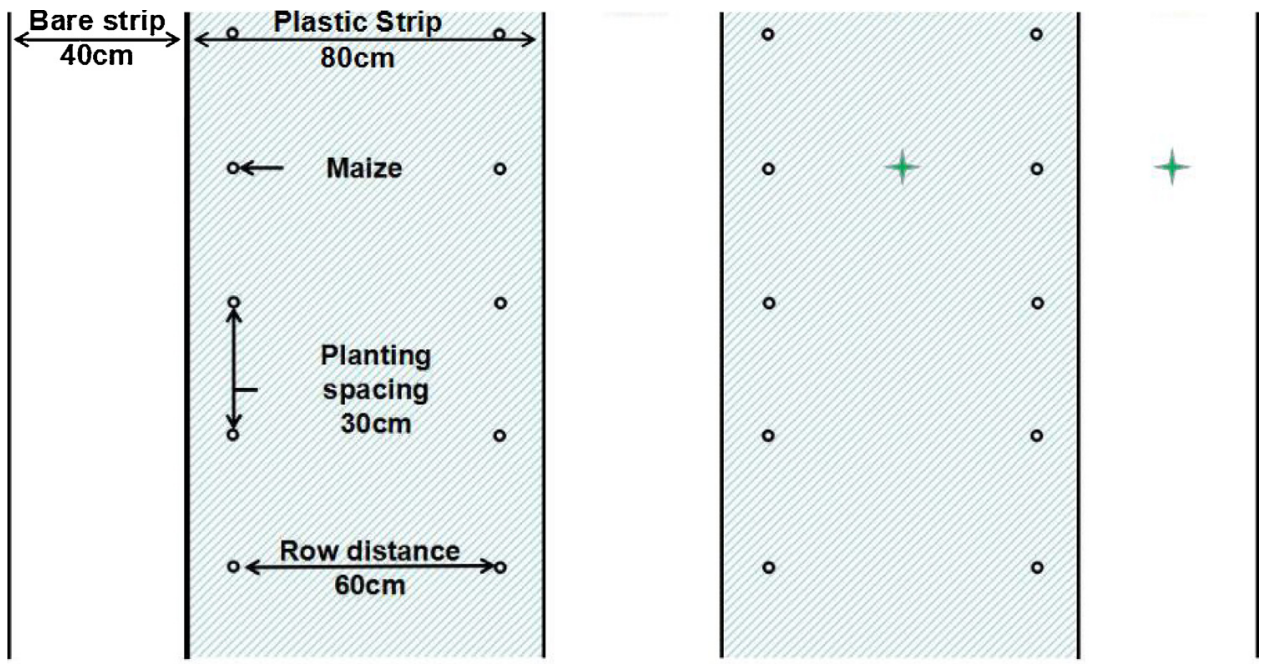

\section{Soil sampling points for soil moisture measurement}

Fig. 1. Field layout of the partial plastic mulching treatment and the locations of measurement points for soil moisture.

weather variables (see 2.5.1). Measured LAI has been reported in our previous study, where we observed PM accelerated the development of LAI in 2015 and 2016 year (Chen et al., 2017). For the LAI measurement method and details on how we obtained weather variables (solar radiation, amount of rainfall, air temperature, relative humidity, and wind speed), please see Chen et al. (2017).

\subsection{Governing equations for soil water transport}

We used HYDRUS-2D (Šimůnek et al., 1994) to simulate the soil water transport. The code used the Galerkin finite element method to numerically solve the governing Richards equation (Richards, 1931):

$\frac{\partial \theta(h)}{\partial t}=\frac{\partial}{\partial x}\left[K(h) \frac{\partial h}{\partial x}\right]+\frac{\partial}{\partial z}\left[K(h) \frac{\partial h}{\partial z}+K(h)\right]-S(h)$

where $\theta$ was the volumetric soil water content $\left(\mathrm{cm}^{3} \mathrm{~cm}^{-3}\right)$; h was the pressure head $(\mathrm{cm}) ; \mathrm{K}(\mathrm{h})$ was the unsaturated hydraulic conductivity $\left(\mathrm{cm} \mathrm{day}^{-1}\right)$; $\mathrm{t}$ was time (day); $\mathrm{x}$ and $\mathrm{z}$ were the horizontal and vertical coordinates $(\mathrm{cm})$; S was the sink term $\left(\right.$ day $\left.^{-1}\right)$.

The soil water retention curve and the unsaturated hydraulic conductivity function were estimated using van GenuchtenMualem constitutive relationships (Van Genuchten, 1980):

$S_{e}(\mathrm{~h})=\frac{\theta(\mathrm{h})-\theta_{r}}{\theta_{s}-\theta_{r}}=\frac{1}{\left(1+|\alpha h|^{n}\right)^{m}}$

$K(\theta)=K_{s} S_{e}^{l}\left[1-\left(1-S_{e}^{l / m}\right)^{m}\right]^{2}$

where $S_{e}$ was the degree of saturation, $h$ was the water potential $(\mathrm{cm}), \theta$ was the volumetric water content $\left(\mathrm{cm}^{3} \mathrm{~cm}^{-3}\right), \theta_{\mathrm{s}}$ and $\theta_{\mathrm{r}}$ were the saturated and residual water contents $\left(\mathrm{cm}^{3} \mathrm{~cm}^{-3}\right)$, respectively, while $\mathrm{m}(-)$ and $\mathrm{n}(\mathrm{m}=1-1 / \mathrm{n})(-)$ were shape parameters, 1 was a pore connectivity parameter $(-), K_{s}$ was the saturated hydraulic conductivity $\left(\mathrm{cm}\right.$ day $\left.^{-1}\right)$.

The root water extraction was computed according to the Feddes model (Feddes et al., 1978):

$S(h)=\tau(h) \beta(x, z) T_{p} L_{t}$

where $T_{p}$ was the potential transpiration rate $\left(\mathrm{cm} \mathrm{day}^{-1}\right), \mathrm{L}_{t}$ was the surface length associated with transpiration $(\mathrm{cm}), \beta(\mathrm{x}, \mathrm{z})$ was the root water uptake distribution function $\left(\mathrm{cm}^{-2}\right)$ and $\tau(\mathrm{h})$ was the root water uptake stress reduction function $(0<\tau<1)$. In Hydrus, the root water uptake was assumed to be zero when the pressure heads close to saturation (h1). When the pressure heads below the wilting point pressure head (h4), water uptake was also assumed to be zero. Water uptake was considered optimal between pressure heads h2 and h3, whereas for pressure head between h3 and h4 (or h1 and h2), water uptake decreased (or increased) linearly with heads. Hydrus-2D provided a database of root water uptake parameters for different crops.

\subsection{Three methods to represent rainfall infiltration in field with plastic mulching}

Fig. 2(A) shows the two methods which were proposed by previous studies (Han et al., 2015; Li et al., 2015; Liu et al., 2013; Filipovic et al., 2016; Dusek et al., 2010): 'BP' - bare strip and plastic strip; ' $\mathrm{BP}+$ ' - bare strip and plastic strip with integrating the process of film side infiltration by increasing the rainfall infiltration amount in bare strip. The impervious plastic cover was represented by a 'no-flux' boundary and the bare soil strip was defined as an 'atmospheric' boundary. For BP, the rainfall amount in the bare strip 


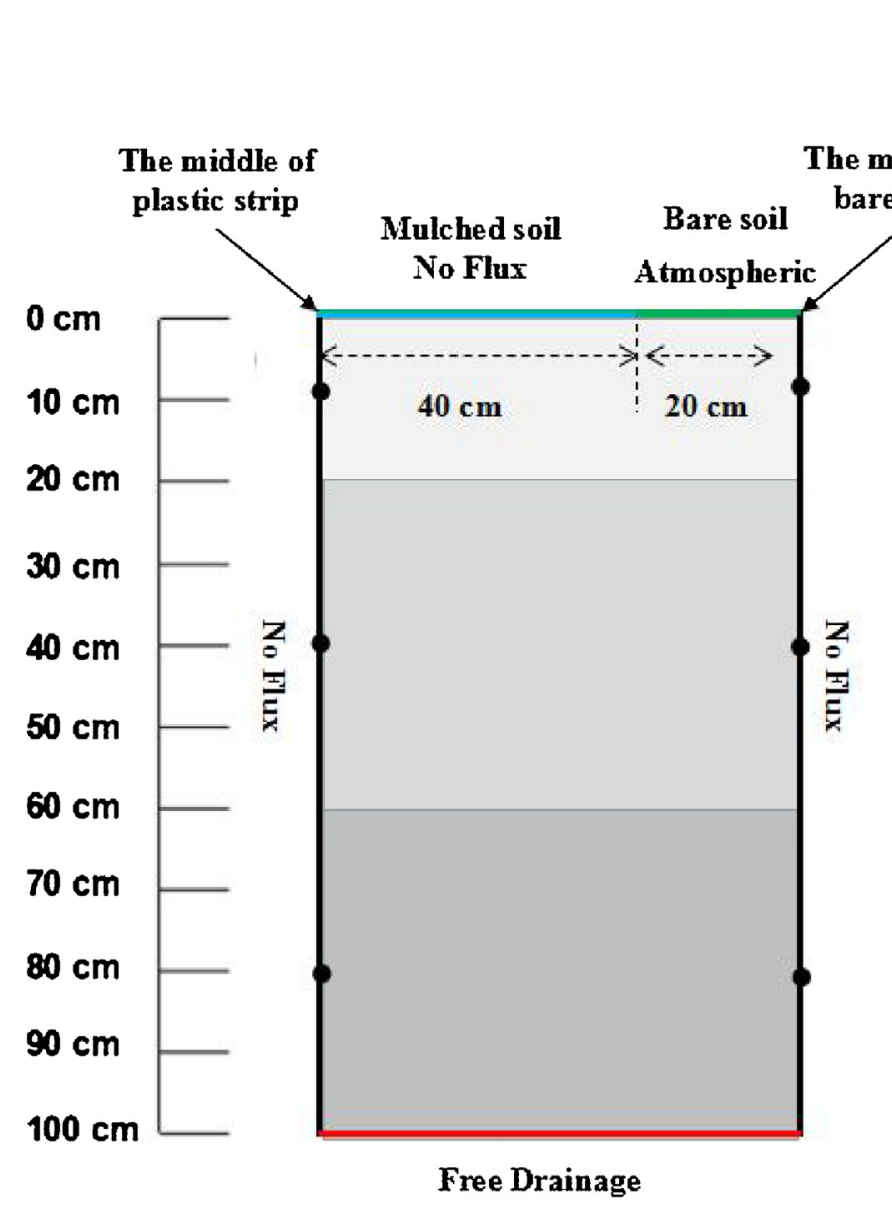

(A)

\section{Infiltration from \\ planting position \\ Variable Flux}

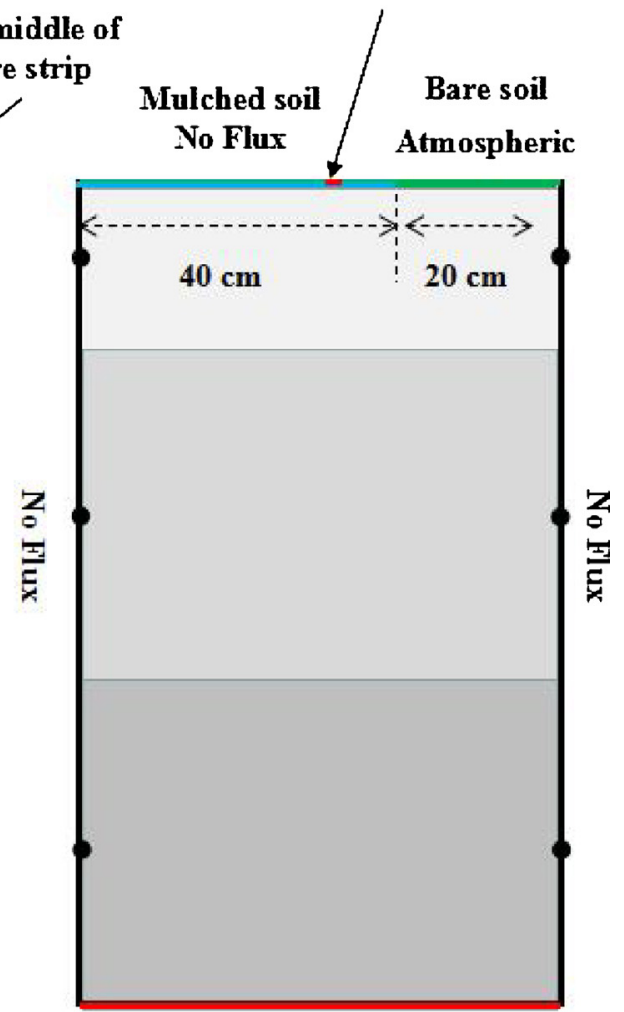

Free Drainage
(B)

Fig. 2. Scheme of boundary conditions in this modelling study: (A) BP and BP+; (B) BPH.

equaled the rainfall amount in meteorological record. For BP+, the rainfall quantity in the bare strip $\left(\mathrm{R}_{\text {bare }}, \mathrm{mm}\right)$ was calculated as:

$\mathrm{R}_{\text {bare }}=\mathrm{R}_{\text {met }} \times\left(\mathrm{W}_{\text {plastic }}+\mathrm{W}_{\text {bare }}\right) / \mathrm{W}_{\text {bare }}$

Where the $R_{\text {met }}$ was the rainfall amount in meteorological record $(\mathrm{mm}), \mathrm{W}_{\text {plastic }}$ was the width of plastic strip $(\mathrm{cm})$ and $\mathrm{W}_{\text {bare }}$ was the width of the bare strip $(\mathrm{cm})$.

In this study, we proposed a third, new strategy which took into account the rainfall canopy redistribution and film side infiltration: 'BPH' - bare strip, plastic strip and planting hole method. As shown as in Fig. 2(B), the "no-flux" boundary was imposed on the plastic strip and the "atmospheric" boundary was imposed on the bare strip. Unlike the other two methods, a $2 \mathrm{~cm}$ 'variable flux' boundary was imposed in the planting hole position to take the rainfall redistribution caused by canopy. The canopy redistribution was defined as on the one hand the rainfall intercepted by the maize leaves and transferred along the stem (stem-flow) and on the other hand the rainfall which reached the ground directly (through-fall). In our case, we adopted the relationship of stem-flow/through-fall (S/T) and incident rainfall $(\mathrm{R}, \mathrm{mm})$ proposed by Martello et al. (2015). This relationship assumed that the $\mathrm{S} / \mathrm{T}$ decreased logarithmically at increasing values of incident rainfall under a closed maize canopy and during the growth period, it increased with the maize canopy cover:

$\mathrm{S} / \mathrm{T}=\mathrm{a} \cdot[\ln (\mathrm{R})+\mathrm{b}]\left(\right.$ ifLAI $\left.\geq \mathrm{LAI}_{\text {closed }}\right)$

$\mathrm{S} / \mathrm{T}=\left(\mathrm{LAI} / \mathrm{LAI}_{\text {closed }}\right) \cdot[\mathrm{a} \cdot \ln (\mathrm{R})+\mathrm{b}]\left(\right.$ ifLAI $\left.<\mathrm{LAI}_{\text {closed }}\right)$ where S/T was the ratio of stem-flow to through-fall, LAI was the leaf area index, and $\mathrm{LAI}_{\text {closed }}$ was the leaf area index when the maize canopy reached the closed condition. The $\mathrm{a}$ and $\mathrm{b}$ were empirically fitted parameters, and they were -1.356 and 7.418 respectively (Martello et al., 2015).

Then, the rainfall infiltration in the bare strip $\left(R_{\text {bare }}\right)$ was calculated by:

$\mathrm{R}_{\text {bare }}=\mathrm{R}_{\text {met }} \times[1 /(\mathrm{S} / \mathrm{T}+1)]$

where $R_{\text {met }}$ was the rainfall amount in meteorological record $(\mathrm{mm})$, and $\mathrm{S} / \mathrm{T}$ was the ratio of stem-flow to through-fall (-).

The rainfall infiltration from the planting hole $\left(\mathrm{R}_{\mathrm{H}}\right)$ was calculated as:

$\mathrm{R}_{\mathrm{H}}=\mathrm{R}_{\text {met }} \times[1-1 /(\mathrm{S} / \mathrm{T}+1)] \times\left(\mathrm{W}_{\text {plastic }}+\mathrm{W}_{\mathrm{H}}+\mathrm{W}_{\text {bare }}\right) / \mathrm{W}_{\text {bare }}$

Where $\mathrm{W}_{\mathrm{H}}$ was the width of planting hole $(\mathrm{cm})$.

In our case, because the maize was planted near the plastic film side (Fig. 1) and to simplify our calculation, we did not set a special boundary for film side. Instead, we assumed the film side infiltration took place in the planting hole position. Thus the rainfall infiltration from the film side $\left(\mathrm{R}_{\mathrm{FS}}\right)$ was calculated as:

$\mathrm{R}_{\mathrm{FS}}=\mathrm{R}_{\mathrm{met}} \times[1 /(\mathrm{S} / \mathrm{T}+1)] \times \mathrm{W}_{\text {plastic }} / \mathrm{W}_{\mathrm{H}}$

As the results showed that the scenario $\mathrm{BPH}$ was the most realistic, we applied this scenario to compare PM with NM in the rest of this study. In NM, a similar $2 \mathrm{~cm}$ 'variable flux' boundary was imposed in the sowing position to take the rainfall redistribution 
Table 2

Soil hydraulic parameters measured by pressure plate and inversion.

\begin{tabular}{lllllll}
\hline Estimated method & Soil layer $(\mathrm{cm})$ & $\theta_{\mathrm{r}}$ & $\theta_{\mathrm{S}}$ & $\alpha$ & $\mathrm{n}$ & $\mathrm{K}_{\mathrm{s}}$ \\
\hline Measured by pressure & $0-20$ & 0.129 & 0.492 & 0.014 & $1.571-$ \\
plate & $20-60$ & 0.13 & 0.433 & 0.007 & $1.846-$ \\
& $60-100$ & 0.123 & 0.515 & 0.017 & 1.560 & - \\
Inversion result & $0-20$ & 0.1143 & 0.417 & 0.0059 & 1.625 & 10.58 \\
& $20-60$ & 0.0866 & 0.494 & 0.0077 & 1.765 & 24.85 \\
& $60-100$ & 0.0546 & 0.500 & 0.0052 & 1.870 & 74.66 \\
\hline
\end{tabular}

Notes: $\theta_{\mathrm{r}}$ is the residual water content $\left(\mathrm{L}^{3} \mathrm{~L}^{-3}\right) ; \theta_{\mathrm{s}}$ is the saturated water content $\left(\mathrm{L}^{3} \mathrm{~L}^{-3}\right) ; \mathrm{K}_{\mathrm{s}}$ is the saturated hydraulic conductivity $\left(\mathrm{cm} \mathrm{day}^{-1}\right) ; \alpha\left(\mathrm{L}^{-1}\right)$ and $\mathrm{n}(-)$ are empirical coefficients that affect the shape of the hydraulic functions.

caused by canopy, and other parts of the upper boundary were expressed as an 'atmospheric' boundary.

\subsection{Model parameterization}

\subsubsection{Daily potential evaporation and transpiration}

With the collected meteorological data, the reference crop evapotranspiration $\left(\mathrm{ET}_{0}\right)$ was computed using the Penman-Monteith combination equation (Allen et al., 1998). Then the crop evaoptranspiration was calculated by multiplying $\mathrm{ET}_{0}$ by crop coefficient $\left(K_{c}\right)$ (Allen et al., 1998). The $K_{c}$ for different growing stage was determined with eddy covariance system in the same research site during 2011-2013 (Gong et al., 2017). The $\mathrm{K}_{\mathrm{c}}$ at initial stage, middle stage, and late stage were $0.22,0.91$ and 0.94 for PM, and 0.27 , 1.01 and 0.99 for NM. Potential evaporation and transpiration could be calculated separately from crop evaoptranspiration using Beer's law which partitioned the solar radiation component of the energy budget via interception by the leaf area index (Ritchie, 1972). In Hydrus-2D, calculated daily potential evaporation was applied in 'atmospheric' boundary to calculate the actual evaporation, and potential transpiration was applied in Eq. (4) and Eq. (1) to calculate the actual root water uptake.

\subsubsection{Soil hydraulic parameters}

In each horizon, three un-disturbed soil samples were taken in the fallow period between the 2015 and 2016 growing seasons with brass rings $7.8 \mathrm{~cm}$ in diameter and $2.0 \mathrm{~cm}$ in height and then placed on a pressure plate apparatus following the procedures described by Dane and Hopmans (2002). The soil water content was measured at matric potentials of $-10,-40,-70,-100,-300,-700,-1000$, -5000 , and $-15,000 \mathrm{~cm} \mathrm{H}_{2} \mathrm{O}$, and then, the values of parameters $\theta_{\mathrm{r}}, \theta_{\mathrm{s}}, \alpha$ and $\mathrm{n}$ were estimated by the RETC code (Van Genuchten et al., 1991). We used the fitted RETC parameters as a starting value to perform an inversion for the hydraulic parameters based on the observed soil water content in NM in 2015 which has been reported in Chen et al. (2017). The measured and inversed soil hydrualic parameters were shown in Table 2. In Hydrus-2D, the soil hydraulic parameters were applied in Eqs. (1)-(3) to describe the water continuous transport in soil medium.

\subsubsection{Root distribution}

Considering vertical differences in maize root density were stronger than the horizontal differences, and differences in root density among inter-row positions were relatively small (Anderson, 1987; Anderson, 1988; Liedgens and Richner, 2001; Qin et al., 2006), only vertical differences in maize root density were taken into account in this study. Maize root distribution was calculated with model proposed by Vrugt et al. (2001):

$\beta(\mathrm{z})=\left[1-\frac{z}{Z_{m}}\right] e^{-\frac{P_{z}}{Z_{m}}\left|z^{*}-z\right|}$

where $Z_{m}$ was the maximum rooting depth in the vertical direction; $\mathrm{z}^{*}$ was an empirical parameter to describe the location of the maximum water uptake in the vertical direction; and $\mathrm{P}_{\mathrm{z}}$ was an empirical parameter describing the non-symmetrical root geometry in the vertical direction. Considering the sowing depth, $\mathrm{z}^{*}$ was set as $10 \mathrm{~cm}$. Since most of the maize root system was concentrated in the 0-60 cm depth (Asadi et al., 2002; Zhou et al., 2008; Gheysari et al., 2009), the depth of the root zone was set as $70 \mathrm{~cm}$ in this study. $P_{z}$ was set to 1.0 according to Vrugt et al. (2001). Gao et al. (2014) found that although the plastic mulching system resulted in a greater root density than the un-mulched system, it did not alter the relative vertical distribution of maize roots. Therefore, the same parameters of the root density distribution were used for NM and PM systems in this study. The root distribution model will be applied in Eq. (4) to calculate the spatial distribution of root water uptake.

\subsection{Statistical analysis}

For each soil layer $(0-20 \mathrm{~cm}, 20-60 \mathrm{~cm}$ and $60-100 \mathrm{~cm})$, the average volumetric soil water content was calculated using the observed values. The middle points of each layer in the left boundary and right boundary (as shown in Fig. 2) were selected as the observation points. Peformance of Hydrus-2D was evaluated via the root mean square error (RMSE) and the relative root mean square error (RRMSE) (Feng et al., 2017):

$\mathrm{RMSE}=\sqrt{\frac{\sum_{\mathrm{i}=1}^{\mathrm{n}}\left(S W C_{o b s, i}-S W C_{\bmod e l, i}\right)^{2}}{n}}$

RRMSE $=$ RMSE $/$ SWC $_{\text {obs, mean }}$

Where SWC ${ }_{\text {obs,i }}$ was the observed soil water content at time $i$, and $\mathrm{SWC}_{\text {model, }}$ was the modeled soil water content at time $\mathrm{i}$, and $\mathrm{n}$ was the number of measurement times, $\mathrm{SWC}_{\mathrm{obs} \text {,mean }}$ was the mean value of the observed soil water content.

With Hydrus-2D, we assessed the 2D distribution of soil water daily, and we computed the average soil water content for the whole growing season as the average value of the daily results. The 2D distribution of the average soil water content in PM minus that in NM was calculated as the difference between PM and NM. All the calculations were completed using Matlab R2015b (MathWorks Inc., USA).

In this study, we adopted the relationship of stem-flow/throughfall and incident rainfall proposed by Martello et al. (2015) which was created in a sub-humid area with annual rainfall distributed fairly uniformly throughout the year. However, under different climate conditions, the parameter a and b in Eq. (6) and (7) might be different. Therefore we analyzed the sensitivity of soil water content to parameters $a$ and $b$. The sensitivity coefficient of $a$ or $b$ was calculated during the growing season of 2015 using a single factor sensitivity analysis method that was reported in Liu et al. (2013). Normally, the practice of sensitivity analysis was to change parameters by $1 \%$ to obtain the sensitivity coefficient, however, as suggested in Liu et al. (2013), the magnitude of variation of a or b was set here at $10 \%$ to avoid possible disturbances associated with the numerical solving process.

\section{Results}

\subsection{Comparison of the performance of different treatment} methods for rainfall infiltration in $P M$

Fig. 3 shows the simulated and measured SWC in different soil layers and positions, and Table 3 shows the corresponding RMSE and RRMSE. The BP scenario did not reproduce the water content peaks caused by concentrated rainfall at the middle of plastic strip in both years. The performances improved with depth, but in general the RRMSEs were poor $(>0.3)$ and therefore this scenario was 


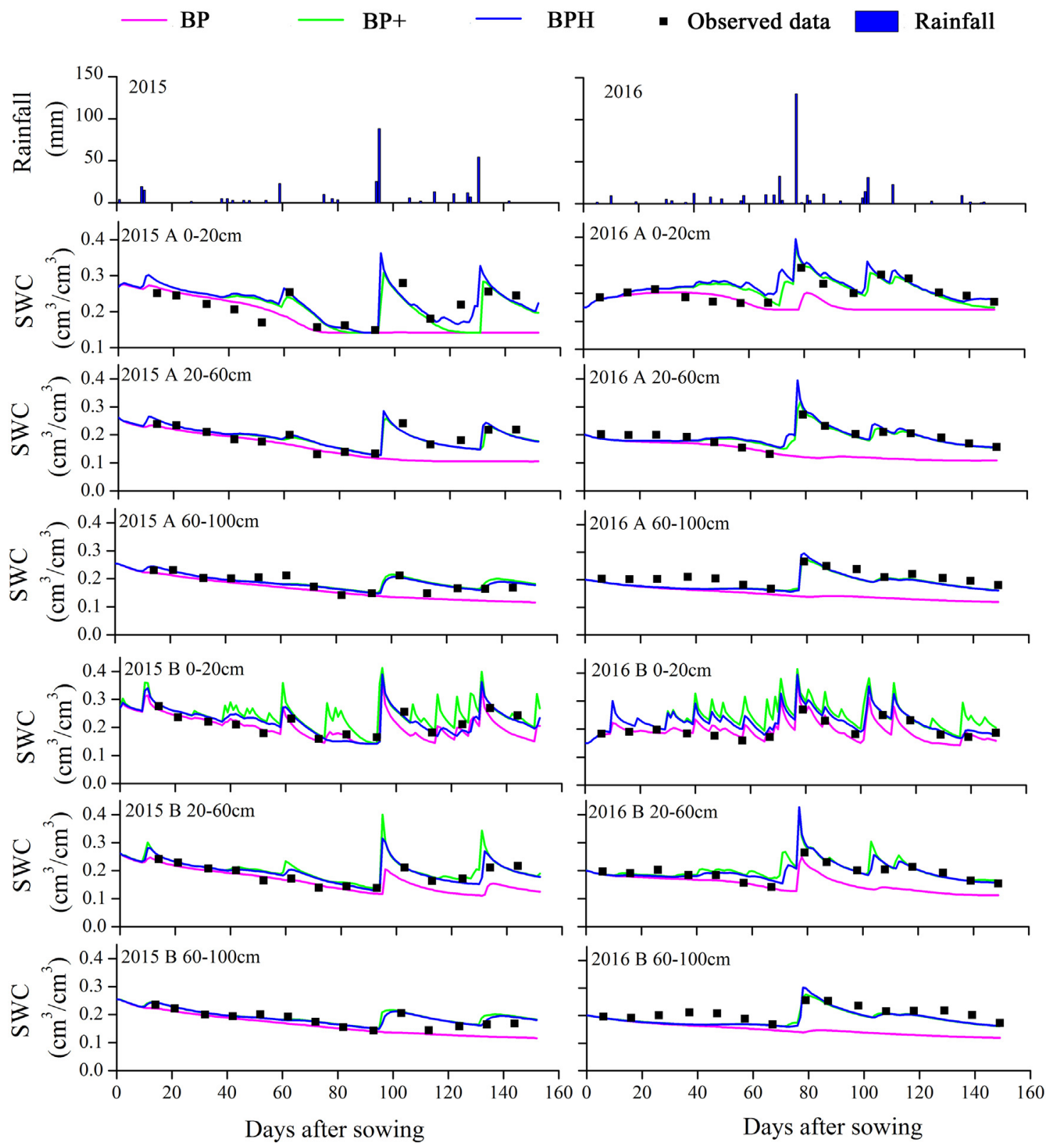

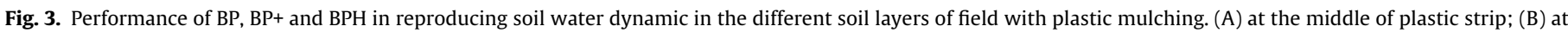
the middle of bare strip.

unsuitable to represent the field context. At the middle of bare strip, simulation BP was doing better than under the plastic strip in 2015 (the year with rainfall lower than the historic mean) with RMSEs ranging from 0.029 to $0.035 \mathrm{~cm}^{3} / \mathrm{cm}^{3}$, and RRMSEs ranging from 0.150 to 0.190 in different soil layers. However, in 2016, a year with rainfall closer to the historic mean, the RMSE in $20-60 \mathrm{~cm}$ and $60-100 \mathrm{~cm}$ at the middle of bare strip was $0.043 \mathrm{~cm}^{3} / \mathrm{cm}^{3}$ and $0.070 \mathrm{~cm}^{3} / \mathrm{cm}^{3}$, and the RRMSE was 0.224 and 0.334 respectively, which were not convincing. The soil water content was underestimated in those two layers in 2016.

Under the mulched strip, the difference between scenarios BP+ and BPH was minimal:BP+ resulted in a slightly lower soil water content than BPH in the upper soil layer in 2015 and 2016. Deeper down, the differences became small. The RRMSEs ranged from 0.083 to 0.165 in different soil layers over these two years for BP+, ranged from 0.089 to 0.151 for $\mathrm{BPH}$. Both scenarios could therefore be considered adequate under the mulched strip. Nonetheless, the two scenarios yielded different results in the bare strip, where BP+ produced higher soil water content in $0-20 \mathrm{~cm}$ than $\mathrm{BPH}$ in both years (Fig. 3). In 2016, this led to a clear overestimation of SWC in 0-20 cm (Table 3). We can conclude that the BPH simulation yielded the best results in 2015 and 2016 at the middle of bare strip with RMSEs ranging from 0.016 to $0.032 \mathrm{~cm}^{3} / \mathrm{cm}^{3}$ and RRMSEs ranging from 0.086 to 0.163 in the different soil layers.

For the BPH scenario, the sensitivity of soil water content to the change of rainfall redistribution parameter a and b (Eq. (6) and (7)) was shown in Table $4.10 \%$ change of parameter $\mathrm{a}$ and $\mathrm{b}$ resulted in $0.003 \%-0.108 \%, 0.002 \%-0.239 \%$ change of soil water content in different soil layers and positions. The sensitivity of soil water content to $a$ and $b$ declined with increasing soil depth. Those results indicate the soil water content has very low sensitivity to the parameter a and $\mathrm{b}$.

\subsection{Predicted spatial variation of soil water content in NM and} $P M$

As BPH performed better to reproduce our field data than BP and $\mathrm{BP}+$, we used only this scenario to study the spatial soil water dis- 
Table 3

The root mean square error (RMSE) and relative root mean square error (RRMSE) for the simulation with BP, BP+ and BPH in plastic mulch field in 2015 and 2016 year.

\begin{tabular}{|c|c|c|c|c|c|c|}
\hline \multirow[t]{2}{*}{ Treatments } & \multirow[t]{2}{*}{ Positions } & \multirow[t]{2}{*}{ Soil Depth $(\mathrm{cm})$} & \multicolumn{2}{|l|}{2015} & \multicolumn{2}{|l|}{2016} \\
\hline & & & $\operatorname{RMSE}(\mathrm{cm} 3 / \mathrm{cm} 3)$ & RRMSE & RMSE $(\mathrm{cm} 3 / \mathrm{cm} 3)$ & RRMSE \\
\hline \multirow[t]{6}{*}{$\mathrm{BP}$} & \multirow[t]{3}{*}{ Middle of plastic strip } & $0-20$ & 0.065 & 0.302 & 0.062 & 0.301 \\
\hline & & $20-60$ & 0.062 & 0.325 & 0.071 & 0.366 \\
\hline & & $60-100$ & 0.034 & 0.183 & 0.071 & 0.338 \\
\hline & \multirow[t]{3}{*}{ Middle of bare strip } & $0-20$ & 0.032 & 0.150 & 0.025 & 0.124 \\
\hline & & $20-60$ & 0.035 & 0.190 & 0.043 & 0.224 \\
\hline & & $60-100$ & 0.029 & 0.161 & 0.070 & 0.334 \\
\hline \multirow[t]{6}{*}{$\mathrm{BP}+$} & \multirow{3}{*}{ Middle of plastic strip } & $0-20$ & 0.035 & 0.165 & 0.027 & 0.131 \\
\hline & & $20-60$ & 0.019 & 0.101 & 0.016 & 0.083 \\
\hline & & $60-100$ & 0.018 & 0.099 & 0.024 & 0.112 \\
\hline & \multirow{3}{*}{ Middle of bare strip } & $0-20$ & 0.030 & 0.142 & 0.056 & 0.281 \\
\hline & & $20-60$ & 0.023 & 0.123 & 0.022 & 0.114 \\
\hline & & $60-100$ & 0.018 & 0.097 & 0.023 & 0.110 \\
\hline \multirow{6}{*}{$\mathrm{BPH}$} & \multirow{3}{*}{ Middle of plastic strip } & $0-20$ & 0.032 & 0.151 & 0.031 & 0.149 \\
\hline & & $20-60$ & 0.020 & 0.105 & 0.018 & 0.092 \\
\hline & & $60-100$ & 0.017 & 0.089 & 0.025 & 0.119 \\
\hline & \multirow[t]{3}{*}{ Middle of bare strip } & $0-20$ & 0.022 & 0.104 & 0.032 & 0.163 \\
\hline & & $20-60$ & 0.020 & 0.108 & 0.023 & 0.118 \\
\hline & & $60-100$ & 0.016 & 0.086 & 0.026 & 0.123 \\
\hline
\end{tabular}
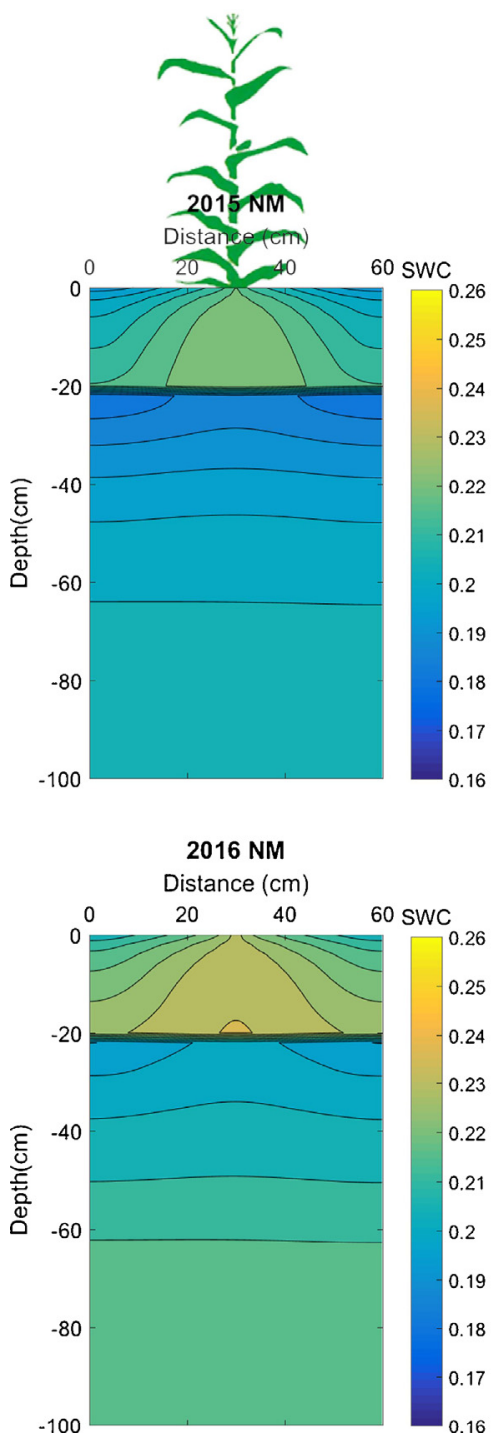

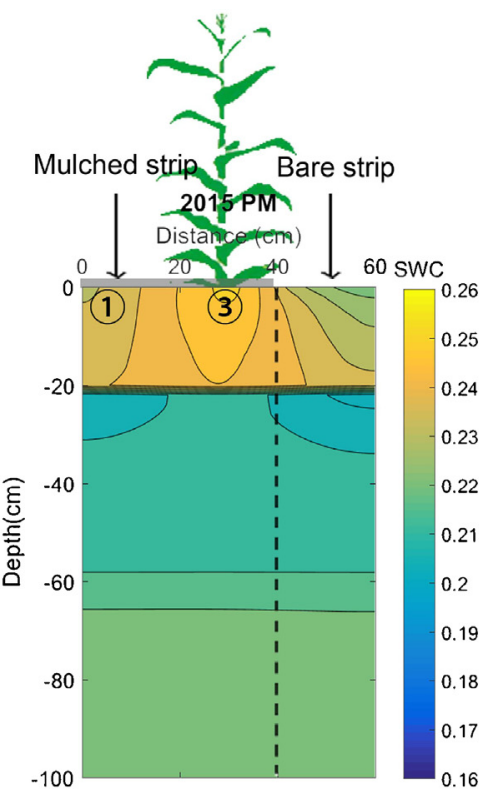

2016 PM

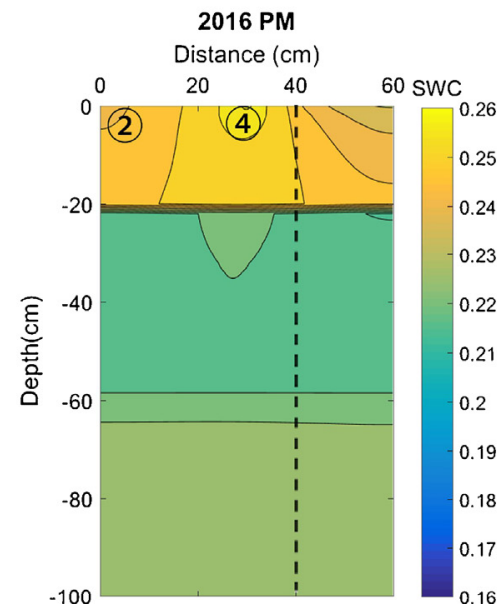

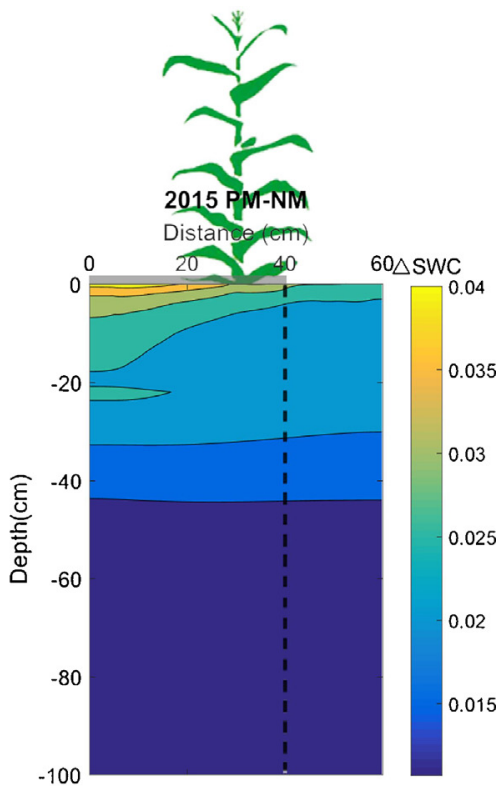

2016 PM-NM

Distance $(\mathrm{cm})$

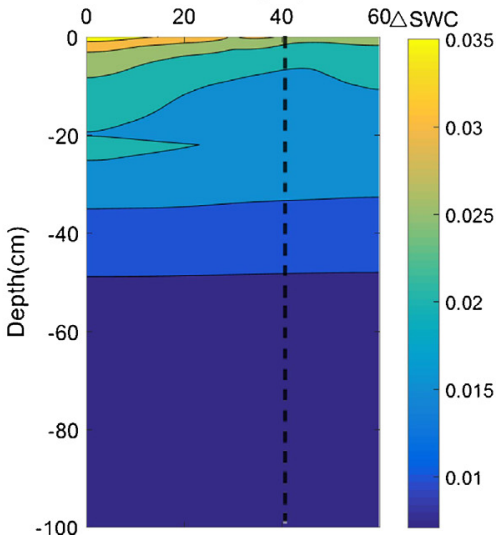

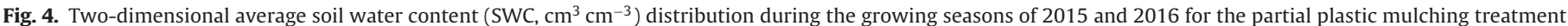
(PM) and the no mulch treatment (NM), and the comparison of their differences (PM-NM). 
Table 4

Sensitivity of soil water content to the $10 \%$ change of parameters a and $b$ in the rainfall redistribution model for $\mathrm{BPH}$ simulation.

\begin{tabular}{llll}
\hline Parameters & Soil layers $(\mathrm{cm})$ & \multicolumn{2}{l}{ Positions } \\
\cline { 3 - 4 } & & Mulch strip & Bare strip \\
\hline a & $0-20$ & $0.108 \%$ & $0.099 \%$ \\
& $20-60$ & $0.095 \%$ & $0.080 \%$ \\
& $60-100$ & $0.003 \%$ & $0.039 \%$ \\
b & $0-20$ & $0.132 \%$ & $0.239 \%$ \\
& $20-60$ & $0.095 \%$ & $0.108 \%$ \\
& $60-100$ & $0.002 \%$ & $0.034 \%$ \\
\hline
\end{tabular}

tribution in NM and PM. Fig. 4 shows the simulated 2D distribution of the average soil water content under NM and PM treatments and their difference $(\triangle S W C)$. The simulation indicated that the top horizon $(0-20 \mathrm{~cm})$ contained more water than deeper in the profile for both years, and the water distribution in the top horizon showed high spatial variation. In PM, the bare strip was drier on average than the plastic strip, and the highest average SWC occurred near the planting hole (labelled with (3) and (4) in Fig. 4). The center zone of plastic strip (labelled with (1) and (2) in Fig. 4) was drier than the zone near the planting hole and the bare strip was direst.

The $\triangle$ SWC ranged from $0.011 \mathrm{~cm}^{3} \mathrm{~cm}^{-3}$ to $0.043 \mathrm{~cm}^{3} \mathrm{~cm}^{-3}$ for the 2015 water conditions and from $0.007 \mathrm{~cm}^{3} \mathrm{~cm}^{-3}$ to $0.038 \mathrm{~cm}^{3} \mathrm{~cm}^{-3}$ for 2016 . The positive influence of PM on the soil moisture availability was higher in the top layer than in deeper layers. The $\triangle S W C$ in the center of the plastic strip was highest, and it decreased towards the planting holes and bare strip. PM improved the SWC not only in the plastic strip but also in the bare strip.

\section{Discussion}

Our results suggest that the performance of Hydrus-2D in rainfed field with plastic mulching depends strongly on the way the incoming rainfall is partitioned over the different types of surface boundaries and whether or not canopy redistribution is taken into account. Previous researches in arid regions suggested that Hydrus2D could simulate the soil moisture dynamics well without taking into account these processes (Han et al., 2015; Li et al., 2015; Liu et al., 2013), probably because in these regions rainfall amounts are much smaller and drip irrigation is dominating the soil water dynamics under the plastic sheet. However, in rain-fed semi-arid areas, rainfall is the main soil water source and neglecting film side infiltration obviously leads to a reduction of the amount of water entering in the soil. In our case, about $67 \%$ of incoming water would be omitted if the film side infiltration is not taken into account, explaining why the performance of the BP simulations is unsatisfactory.

The difference between $\mathrm{BP}+$ and $\mathrm{BPH}$ is more subtle, since the amount of rainfall is the same for both scenarios, but the infiltration location is different: in $\mathrm{BP}+$ all rainfall goes to the bare strip, whereas in BPH part of it infiltrates in the planting holes. Rain-fed semi-arid area is usually characterized by high wetting-drying frequency because of limited rainfall and the lack of irrigation (Borken and Matzner, 2009). While the BP+ led to obvious stronger wetting intensity compared to BPH (Fig. 3). This is the main reason why $\mathrm{BP}+$ simulation is not as good as BPH in rain-fed semi-arid area. Canopy redistribution is an important process in rainfall infiltration in maize field. Martello et al. (2015) observed that $78 \%$ of the rainfall was intercepted by the maize leaves under closed canopy conditions and transferred along the stem into soil and only $22 \%$ reached the ground directly. Paltineanu and Starr (2000) also obtained similar results. Our results suggest it is absolutely necessary to take rainfall canopy redistribution into consideration to simulate the soil water dynamic in rain-fed field with plastic mulching.
Our simulation with BPH shows that the highest SWC occurs in the zone near the planting hole, the center zone of the plastic strip was drier, and the bare strip was the driest. Lowest soil moisture levels in the bare strip probably due to a higher exposure to evaporation. The lower soil moisture at the middle of plastic strip results from the fact that the plastic cover impedes rainfall infiltration. The simulation also suggested that PM not only improved the average SWC in the plastic strip, but also remarkably improved the SWC in the bare strip as compared to NM. This is a result of lower evaporation in PM and soil water transport between the plastic and bare strips. In PM, the evaporation is largely reduced, which then leads to higher soil water content. During the drying stage, evaporation first leads to a reduction in soil moisture in the bare strip; then, because of the existing water potential gradient between the mulched strip and the bare strip, water is transported from the plastic strip to the bare strip, which partly compensates for the water loss in the bare strip. The improved soil moisture status in the bare strip of PM should be taken into account to evaluate the agronomical and environmental effects of PM.

Nevertheless, in this study we only aimed at representing partial plastic mulching with PE material and following the common plastic-bare strip pattern as widely available on the Loess Plateau and in the Northeast of China. However, new plastic mulching patterns, such as two ridges and furrow plastic mulching (Zhou et al., 2009), as well as new biodegradable materials (Saglam et al., 2017; Kasirajan and Ngouajio, 2012) are currently being developed. Especially for plastic mulching with biodegradable materials, some extra processes should be taken into account, since these plastics decompose faster and present cracks changing the infiltration processes. In this case a no-flux boundary which is constant in time may not be suitable for the mulched strip.

\section{Conclusion}

In the present study, we tested the performance of three strategies to represent rainfall infiltration in rain-fed fields with partial plastic mulching and applied the optimized strategy to investigate the spatial variation of soil moisture. The comparison demonstrated that when rainfall canopy redistribution and film side infiltration were neglected, Hydrus-2D failed to reproduce the soil water dynamics in all soil layers in the plastic strip and in the deep soil layers $(20-60 \mathrm{~cm}$ and $60-100 \mathrm{~cm}$ ) in the bare strip as a result of underestimation of rainfall infiltration. Integration of the process of film side infiltration by increasing the rainfall amount in bare strip results in too wet conditions in the bare strip as a result of overestimation of rainfall infiltration in bare strip. Hydrus-2D shows good performance when both rainfall canopy redistribution and film side infiltration are taken into account. This suggests that rainfall redistribution and film side infiltration are not negligible and should be correctly added as boundary conditions in the numerical solution of the Richards equation in rain-fed field with plastic mulching.

Our simulations with the optimized strategy suggest that the highest SWC appears in the zone near the planting hole, the center zone of the plastic strip is drier, and the bare strip is the driest. Compared to the NM, PM not only improves the SWC in the plastic strip but also improves the SWC in the bare strip. This implies to measure soil moisture dynamics and soil processes driven by soil moisture, difference between PM and NM should not only compared in plastic strip, but also should be compared in the zone near planting hole and in the bare strip due to different soil moisture conditions among those locations.

\section{Acknowledgements}

This work was supported by the National Natural Science Foundation of China [grant numbers: 31370522; 31661143011], and 
the Special Fund for Agro-scientific Research in the Public Interest [grant numbers: 201503120]. We thank the University of Liège-Gembloux Agro-Bio Tech and more specifically the research platform Terra Research \& Teaching Center for the scientific stay in Belgium that made this paper possible. We thank the scholarship "Erasmus+ International Credit Mobility" awarded by the University of Liège on behalf of European Commission, for the stay in Gembloux Agro-Bio Tech.

\section{References}

Šimůnek, J., Vogel, T., van Genuchten h, M.T., 1994. The Swms_2d Code for Simulating Water Flow and Solute Transport in Two-dimensional Variably Saturated Media. Riverside: U.S. Salinity Laboratory Agricultural Research Service, USDA.

Allen, R.G., Pereira, L.S., Raes, D., Smith, M., 1998. FAO 56 Irrigation and Drainage Paper: Crop Evapotranspiration. Food and Agriculture Organization, Rome, Italy.

Anderson, E.L., 1987. Corn root-growth and distribution as influenced by tillage and nitrogen-fertilization. Agron. J. 79, 544-549.

Anderson, E.L., 1988. Tillage and n-fertilization effects on maize root-growth and root - shoot ratio. Plant Soil 108, 245-251.

Asadi, M.E., Clemente, R.S., Das Gupta, A., Loof, R., Hansen, G.K., 2002. Impacts of fertigation via sprinkler irrigation on nitrate leaching and corn yield in an acid-sulphate soil in Thailand. Agr. Water Manage. 52, 197-213.

Borken, W., Matzner, E., 2009. Reappraisal of drying and wetting effects on C and N mineralization and fluxes in soils. Global Change Biol. 15, 808-824.

Chen, B., Yan, C., Garré, S., Mei, X., Liu, E., 2017. Effects of a 'one film for 2 years' system on the grain yield, water use efficiency and cost-benefit balance in dryland spring maize (Zea mays L.) on the Loess Plateau. China. Arch. Agron. Soil Sci., http://dx.doi.org/10.1080/03650340.2017.1393530.

Dane, J.H., Hopmans, J.W., 2002. Pressure Plate Extractor. Methods of Soil Analysis. Part 4. Physical Methods. SSSA, Madison.

Deng, X.P., Shan, L., Zhang, H., Turner, N.C., 2006. Improving agricultural water useefficiency in arid and semiarid areas of China. Agric. Water Manage. 80 23-40.

Dong, H., Li, W., Tang, W., Zhang, D., 2009. Early plastic mulching increases stand establishment and lint yield of cotton in saline fields. Field Crop. Res. 111, 269-275.

Dusek, J., Ray, C., Alavi, G., Vogel, T., Sanda, M., 2010. Effect of plastic mulch onwater flow and herbicide transport in soil cultivated with pineapple crop: amodeling stiudy. Agric. Water Manage. 97, 1637-1645.

FAO, 2006. Guidelines for Soil Description. FAO, Rome.

Falkenmark, M., Rockström, J., 2004. Balancing Water for Humans and Nature. Earthscan Publications, London.

Feddes, R.A., Kowalik, P.J., Zaradny, H., 1978. Simulation of field water use and crop yield. John Wiley and Sons, New York

Feng, Y., Cui, N., Gong, D., Zhang, Q., Zhao, L., 2017. Evaluation of random forests and generalized regression neural networks for daily reference evapotranspiration modelling. Agr. Water Manage. 193, 163-173.

Filipovic, V., Romic, D., Romic, M., Borosic, J., Filipovic, L., Mallmann, F.J.K. Robinson, D.A., 2016. Plastic mulch and nitrogen fertigation in growing vegetables modify soil temperature, water and nitrate dynamics: experimental results and a modeling study. Agr. Water Manage. 176, 100-110.

Fisher, P.D., 1995. An alternative plastic mulching system for improved water management in dryland maize production. Agr. Water Manage. 27, 155-166.

Gao, Y.H., Xie, Y.P., Jiang, H.Y., Wu, B., Niu, J.Y., 2014. Soil water status and root distribution across the rooting zone in maize with plastic film mulching. Field Crop. Res. 156, 40-47.

Gheysari, M., Mirlatifi, S.M., Homaee, M., Asadi, M.E., Hoogenboom, G., 2009. Nitrate leaching in a silage maize field under different irrigation and nitrogen fertilizer rates. Agr. Water Manage. 96, 946-954.

Gong, D., Hao, W., Mei, X., Gao, X., Liu, Q., Caylor, K., 2015. Warmer and wetter soil stimulates assimilation more than respiration in rainfed agricultural ecosystem on the china loess plateau: the role of partial plastic film mulching tillage. PLoS One 10, e0136578.

Gong, D.Z., Mei, X.R., Hao, W.P., Wang, H.B., Caylor, K.K., 2017. Comparison of ET partitioning and crop coefficients between partial plastic mulched and non -mulched maize fields. Agr. Water Manage. 181, 23-34

Han, M., Zhao, C.Y., Feng, G., Yan, Y.Y., Sheng, Y., 2015. Evaluating the effects of mulch and irrigation amount on soil water distribution and root zone water balance using HYDRUS-2D. Water 7, 2622-2640.

Kader, M.A., Senge, M., Mojid, M.A., Ito, K., 2017. Recent advances in mulching materials and methods for modifying soil environment. Soil Till. Res. 168 $155-166$.

Kasirajan, S., Ngouajio, M., 2012. Polyethylene and biodegradable mulches for agricultural applications: a review. Agron. Sustain. Dev. 32, 501-529.
Li, X.Y., Shi, H.B., Simunek, J., Gong, X.W., Peng, Z.Y., 2015. Modeling soil water dynamics in a drip-irrigated intercropping field under plastic mulch. Irrig. Sci. 33, 289-302.

Liedgens, M., Richner, W., 2001. Minirhizotron observations of the spatial distribution of the maize root system. Agron. J. 93, 1097-1104.

Liu, M.X., Yang, J.S., Li, X.M., Yu, M., Wang, J., 2013. Numerical simulation of soil water dynamics in a drip irrigated cotton field under plastic mulch. Pedosphere 23, 620-635.

Liu, Q., Chen, Y., Li, W., Liu, Y., Han, J., Wen, X., Liao, Y., 2016. Plastic-film mulching and urea types affect soil CO2 emissions and grain yield in spring maize on the Loess Plateau. China Sci. Rep.-UK 6.

Martello, M., Dal Ferro, N., Bortolini, L., Morari, F., 2015. Effect of incident rainfall redistribution by maize canopy on soil moisture at the crop row scale. Water 7 2254-2271.

NBSC (National Bureau of Statistics of China), 2016. China Statistical Yearbook 2016. China Statistics Press, Beijing.

Paltineanu, I.C., Starr, J.L., 2000. Preferential water flow through corn canopy and soil water dynamics across rows. Soil Sci. Soc. Am. J. 64, 44-54.

Qin, R.J., Stamp, P., Richner, W., 2006. Impact of tillage on maize rooting in a Cambisol and Luvisol in Switzerland. Soil Till. Res. 85, 50-61.

Qin, W., Hu, C.S., Oenema, O., 2015. Soil mulching significantly enhances yields and water and nitrogen use efficiencies of maize and wheat: a meta-analysis. Sci. Rep.-UK 5.

Ren, X., Zhang, P., Liu, X., Ali, S., Chen, X., Jia, Z., 2017. Impacts of different mulching patterns in rainfall-harvesting planting on soil water and spring corn growth development in semihumid regions of China. Soil Res. 55, 285-295.

Richards, L., 1931. Capillary conduction of liquid in porous media. Physics 1 , 318-333.

Ritchie, J.T., 1972. Model for predicting evaporation from a row crop with incomplete cover. Water Resour. Res. 8, 1204-1213.

Rockström, J., Karlberg, L., Wani, S.P., Barron, J., Hatibu, N., Oweis, T., Bruggeman, A., Farahani, J., Qiang, Z., 2010. Managing water in rainfed agriculture-the need for a paradigm shift. Agric. Water Manage. 97, 543-550.

Rost, S., Gerten, D., Bondeau, A., Lucht, W., Rohwer, J., Schaphoff, S., 2008 Agricultural green and blue water consumption and its influence on the global water system. Water Resour. Res. 44, 137-148.

Saglam, M., Sintim, H.Y., Bary, A.I., Miles, C.A., Ghimire, S., Inglis, D.A., Flury, M., 2017. Modeling the effect of biodegradable paper and plastic mulch on soil moisture dynamics. Agr. Water Manage. 193, 240-250.

Tarara, J.M., 2000. Microclimate modification with plastic mulch. Hortscience 35 , 169-180.

Van Genuchten, M.T., Leij, F.J., Yates, S.R., 1991. The RETC Code for Quantifying the Hydraulic Functions of Unsaturated Soils. Robert S. Kerr Environmental Research Laboratory.

Van Genuchten, M.T., 1980. A closed-form equation for predicting the hydraulic conductivity of unsaturated soils. Soil Sci. Soc. Am. J. 44, 892-898.

Vereecken, H., Schnepf, A., Hopmans, J.W., Javaux, M., Or, D., Roose, D.O.T., Vanderborght, J., Young, M.H., Amelung, W., Aitkenhead, M., Allison, S.D. Assouline, S., Baveye, P., Berli, M., Bruggemann, N., Finke, P., Flury, M., Gaiser, T., Govers, G., Ghezzehei, T., Hallett, P., Franssen, H.J.H., Heppell, J., Horn, R., Huisman, J.A., Jacques, D., Jonard, F., Kollet, S., Lafolie, F., Lamorski, K., Leitner, D., McBratney, A., Minasny, B., Montzka, C., Nowak, W., Pachepsky, Y., Padarian, J., Romano, N., Roth, K., Rothfuss, Y., Rowe, E.C., Schwen, A., Simunek, J., Tiktak, A., Van Dam, J., van der Zee, S.E.A.T.M., Vogel, H.J., Vrugt, J.A., Wohling, T., Young, I.M., 2016. Modeling soil processes: review, key challenges, and new perspectives. Vadose Zone J., 15, http://dx.doi.org/10.2136/vzj2015.09.0131.

Vrugt, J.A., Hopmans, J.W., Simunek, J., 2001. Calibration of a two-dimensional root water uptake model. Soil Sci. Soc. Am. J. 65, 1027-1037.

Wu, Y., Huang, F., Jia, Z., Ren, X., Cai, T., 2017. Response of soil water temperature, and maize (Zea may L.) production to different plastic film mulching patterns in semi-arid areas of northwest. China. Soil Till. Res. 166, 113-121.

Xiao, Q., Zhu, L.X., Shen, Y.F., Li, S.Q., 2016. Sensitivity of soil water retention and availability to biochar addition in rainfed semi-arid farmland during a three-year field experiment. Field Crop. Res. 196, 284-293.

Zhao, H., Xiong, Y.C., Li, F.M., Wang, R.Y., Qiang, S.C., Yao, T.F., Mo, F., 2012. Plastic film mulch for half growing-season maximized WUE and yield of potato via moisture-temperature improvement in a semi-arid agroecosystem. Agr. Water Manage. 104, 68-78

Zhou, S.L., Wu, Y.C., Wang, Z.M., Lu, L.Q., Wang, R.Z., 2008. The nitrate leached below maize root zone is available for deep-rooted wheat in winter wheat-summer maize rotation in the North China Plain. Environ. Pollut. 152 $723-730$.

Zhou, L.M., Li, F.M., Jin, S.L., Song, Y.J., 2009. How two ridges and the furrow mulched with plastic film affect soil water: soil temperature and yield of maize on the semiarid Loess Plateau of China. Field Crop. Res. 113, 41-47. 